\title{
A note on the relation between area and intensity in taste
}

DONALD H. McBURNEY ${ }^{2}$

UNIVERSITY OF PITTSBURGH

Taste thresholds as a function of area previously published (Hara, 1955) are reanulyzed and found to be described better by the hyperbolic relation $C \times A^{n}=k$ than an exponential equation. The exponent, $n$, and the constant, $k$, were found to differ among taste compounds.

Bujas and Ostojcic (1941) and Nishida (1943) have reported that the relation between area and concentration at threshold for taste is described by a hyperbola of the form $\mathrm{C} \times \mathrm{A}^{\mathrm{n}}=\mathrm{k}$. Hara (1955) reported the results of an experiment in which he varied area between 1 and $9 \mathrm{~mm}^{2}$ for $\mathrm{NaCl}, \mathrm{MgSO}_{4}$, ace tic acid, sucrose, saccharin, and quinine hydrochloride. He states that his data fit a negative exponential in contrast to the earlier reports. Hara's data are replotted in logarithmic coordinates in Fig. 1. A straight line would indicate a hyperbolic function. It is apparent that the fit is excellent.

Comparison of the correlations between $\log \mathrm{C}$ and $\mathrm{A}$ and between $\log C$ and $\log A$ will give a measure of the goodness of fit to an exponential and hyperbolic equation, respectively. These are given in Table 1. For the hyperbola all fits are excellent (better than -.99). The value of $r$ is generally lower for the

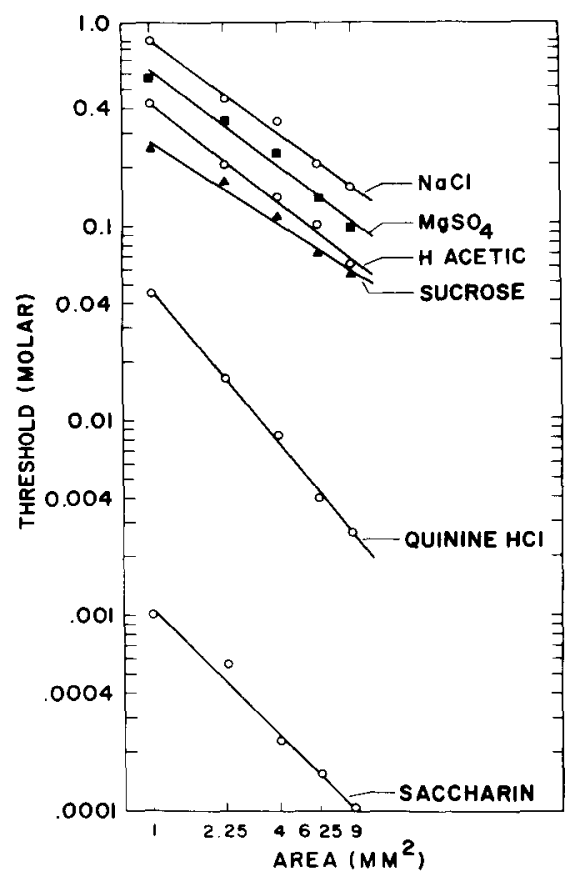

Table 1

\begin{tabular}{lcc} 
& $\log \mathrm{C}$ vs A & $\log \mathrm{C}$ vs Log A \\
\hline $\mathrm{NaCl}$ & -.972 & -.995 \\
$\mathrm{MgSO}_{4}$ & -.993 & -.991 \\
$\mathrm{H}$ Acetic & -.967 & -.996 \\
Sucrose & -.995 & -.994 \\
Quinine $\mathrm{HCl}$ & -.942 & -.998 \\
Saccharine & -.972 & -.992 \\
\hline
\end{tabular}

exponential but, more important, the curves all deviate from an exponential systematically, whereas the deviation from a hyperbola seems to be random. Since any monotonic function will give a high correlation when plotted in any coordinates, the amount of variance unaccounted for is a better means of comparing the two curves. The hyperbola accounts for all but $1 \%$ of the variance, while the exponential leaves $5 \%$ unaccounted for. The hyperbolic function requires one constant while Hara's exponential requires two. A comparison of $n$ and $k$ for Hara's and Bujas's and Ostojcics's data is shown in Table 2. The correspondence between the two experiments is remarkable considering the nonoverlap in areas and the differences in procedure between experiments.

Table 2

\begin{tabular}{lcccc}
\hline & Hara & $\begin{array}{l}\text { Bujas \& } \\
\text { Ostojcic }\end{array}$ & Hara & $\begin{array}{l}\text { Bujas \& } \\
\text { Ostojcic }\end{array}$ \\
\hline $\mathrm{NaCl}$ & .78 & .73 & .88 & .37 \\
$\mathrm{MgSO}_{4}$ & .81 & & .62 & \\
Acetic Acid & .83 & & .42 & \\
Citric Acid & & 0.6 & & .06 \\
Sucrose & .69 & .93 & .27 & .77 \\
Saccharin & 1.07 & & .0011 & \\
Quinine hydrochloride & 1.31 & 1.42 & .046 & .01 \\
\hline
\end{tabular}

\section{REFERENCES}

BUJAS, Z., \& OSTOJCIC, A. La sensibilité gustative en fonction de la surface excitée. Acta Instituti Psychologici Universitatis Zagrebensis, $1941,13,1-20$

HARA, S. Interrelationship among stimulus intensity, stimulated area and reaction time in the human gustatory sensation. Bulletin of the Tokyo Medical and Dental University, 1955, 2, 147-158.

NASHIDA, I. On the summation of the gustatory stimulation. Journal of the Phy siological Society of Japan, 1943, 8, 521. (Cited by Hara, 1955.)

\section{NOTES}

1. Supported by NIH Grant NB 07873-02.

2. Address: Department of Psychology, University of Pittsburgh, Pittsburgh, Pennsylvania 15213.

(Accepted for publication February 19, 1969.) 